Commentary on The Merits of Integrating Accelerated Experiential Dynamic Psychotherapy and Cultural Competence Strategies in the Treatment of Relational Trauma: The Case of "Rosa"

\title{
AEDP and Cultural Competence in Developmental Trauma Treatment
}

\author{
KAREN RIGGS SKEAN ${ }^{\text {a,b }}$ \\ ${ }^{a}$ Graduate School of Applied and Professional Psychology, Rutgers University-New Brunswick, NJ \\ ${ }^{\mathrm{b}}$ Correspondence regarding this article should be sent to Karen Riggs Skean, Graduate School of Applied and \\ Professional Psychology, Rutgers University-New Brunswick, 152 Frelinghuysen road, Piscataway, NJ 08854 \\ Email: kskean@connect.rutgers.edu
}

\begin{abstract}
This commentary discusses the therapy of a complex trauma survivor combining Accelerated Experiential Dynamic Psychotherapy (AEDP) with culturally competent strategies, particularly the use of a shared second language of origin. This combination potentiated the transformation of early affectively and bodily held memories and facilitated a successful outcome. Implications for short-term models and the training of therapists are discussed.
\end{abstract}

Key words: Accelerated Experiential Dynamic Therapy (AEDP); cultural competence; complex PTSD; complex trauma; short-term dynamic psychotherapy; case study; clinical case study

In order for the reader to understand the full context of my comments, I want to begin by establishing that I was the supervisor of the case, as well as the instructor for the Clinical PsyD course in Short-Term Dynamic Psychotherapy in which the author was enrolled at the time. I was able to observe this dyad at work session by session as I reviewed the videotape with Dr. Nicole Vigoda Gonzales, the therapist. I also shared in the excitement and interest of the class when Vigoda Gonzales showed and discussed her work. Dr. Dan Fishman, PCSP's editor, directed the dissertation project that grew from the case and has facilitated her sharing of this moving and lovely work in a structured and systematic way (Vigoda Gonzales, 2018). The work is noteworthy for its conscious combination of both Accelerated Experiential Dynamic Psychotherapy, or AEDP (Fosha, 2000); cultural competence; and the synergy Vigoda Gonzales created between them. Both frameworks privilege the experience of the client; both aim to empower and to provide resources to clients to act authentically from that experience; and both view humans through a non-pathologizing and affirming lens.

\section{THE NATURE OF AEDP AND A SHARED LANGUAGE IN THERAPY}

AEDP is an integrative model that combines a focus on affect, in-the-moment experience, and attachment history. With roots in intensive short-term dynamic therapy (ISTDP), AEDP 
retains from that model the high level of therapist activity and a dynamic understanding of the aliveness of the past in the present. AEDP has broadened to incorporate interpersonal neurobiology, emotion theory, and increasingly, bodily-focused and trauma approaches. In addition, AEDP has also shifted from ISTDP's more confrontational style to one of relentless empathy and validation of the client's moment to moment experience (Fosha, 2000, 2004, 2006; Lipton and Fosha, 2011).

Vital to Vigoda Gonzles' treatment approach is the trauma treatment that lay at its heart - the transformation of sequestered and painful memories through the emotion-focus of AEDP, facilitated by the deliberate and attachment-enhancing use of a shared native language. AEDP aims to have the client experience being both seen and heard, and it was clear that the shared Spanish language, even though not the language of therapy, was an important part of the client feeling seen and heard. It was particularly important for the child within Rosa, still frozen in shame and a sense of brokenness, to be related to in an experience-near way, and that child experienced and encoded those many experiences of traumatizing shaming and blaming in Spanish. To be able to speak them aloud as they were held in vivid, visceral memory was pivotal in allowing the level of emotional processing so healing in AEDP. One important marker supporting this was Vigoda Gonzales's observation that the use of Spanish seemed most important when dealing with early childhood memories, and less salient as current and more recent events were discussed, with language switching or referencing occurring less often as some of the earlier memories had been worked through.

The frame of AEDP also potentiated the effectiveness of the shared language. A shared language alone does not protect from ruptures or automatically create a therapeutic alliance (Gaztambide, 2012). There are still major within-group differences that can generate their own disruptions and misunderstandings. Rather than launching with the assumption that a shared knowledge of Spanish would itself do part of the work of joining, Vigoda Gonzales was carefully tracking her client, aware of those moments when she seemed to be hampered by not using her native language, and at an especially impactful moment disclosed that she herself was a native Spanish speaker, making for a powerful moment of meeting. Rosa responded with evident delight, saying, "This is very helpful because a lot of these things that happened in Spanish have a different feeling to them" (p. 25).

As Vigoda Gonzales stated, her example need not mean we must have such language or ethnic matching for effectiveness, but it does heighten our sense of where and how these memories are held, how we might find way of accessing them, and how there are moments in which this might significantly add to the emotional power of an intervention. For example, encouraging a client to repeat words in the mother language as they heard them in the original memory, even if we don't speak that language, can help access deeper levels of experience. The new multicultural guidelines recently approved by the American Psychological Association (2017) stress the need to remain alert to several important aspects of language as a dimension of multicultural competence, among them awareness of the cognitive and affective components of bilingualism, refraining from assuming cultural sameness even where a shared language exists, and awareness that events encoded in a particular language may have a different level of emotionality attached to them in that language. 
More specific to the psychodynamic framework in which this case was conceptualized, Walsh (2014) talks about the development of a language-based sense of self, the reality that to have more than one language is to have multiple language-based selves. The bodily and emotional substrata of our psychological lives and our relational templates are profoundly related to the language of our early experiences. We learn to relate to others in and through language. This is true for the bilingual therapist as well as for the bilingual client. So Rosa and Vigoda Gonzales would be interacting in the matrix of this complexity of identities. As Vigota Gonzales moved into the frightening world of Rosa's early experiences, Vigoda Gonzales' ability to access and be present with Rosa and to resonate through their shared language helped Rosa's two selves - the later English-speaking self and the early Spanish-speaking self-begin to speak to each other. The language-based reality of the Spanish-speaking child had been held separate and apart from the adult, who had a very different set of experiences, competence, and success in many spheres of life. While the monolingual client may also experience separate child and adult selves, Rosa's child part might have remained more easily held apart by being encoded in a language that was not part of the therapy. What was crucial for Rosa was knowing that her therapist could relate to her early self, and importantly in AEDP terms, that revisiting the experiences of that language-based self did not have to be done alone.

AEDP deserves to be more widely recognized as a trauma treatment. The three-stage model of trauma work prominent in the field since it was introduced by Judith Herman (1994) holds that the therapist must ensure that there is enough safety and stability to do the work of addressing the trauma itself; must engage with the traumatic incident, history or past in some active or transformative way; and must restore to the person their sense of connection to others and to a wider community, repairing the social bonds broken by the trauma.

\section{STAGES ONE AND TWO IN TRAUMA TREATMENT: ESTABLISHING SAFETY AND EXPOSURE}

Different trauma models go about each of these steps in a variety of ways. AEDP, as demonstrated by Vigoda Gonzales' work, addresses the first stage, the establishing of safety, by careful moment-to-moment tracking of the client within the context of an attachment relationship. Our attachment bond mediates and moderates our sense of felt safety. When a responsive and attuned other is present with us, our nervous system is in a different place. We can go places that it would be terrifying to go alone (Bowlby, 1980; Porges, 2011). Rosa let Vigoda Gonzales know at the beginning of therapy how terrifying it was for her to return to the pain of her childhood, how she wanted to limit the work to a current problem, stating "I can't look at this right now, it is too much to deal with... I need to focus on my son" (p. 14). But as the relationship became safer, Rosa was increasingly able to allow herself to feel what she could not before, to acknowledge that her present pain and stuckness related powerfully to the past she had put in the closet. The AEDP goal of "undoing aloneness" allows the presence of the therapist to serve as a steady resource. With safety established and carefully monitored, therapist and client move to the trauma-focused part of the therapy, stage two of trauma work. Different therapeutic models approach this stage in a variety of ways, from the eye movements of Eye Movement Desensitization and Reprocessing (EMDR; Shapiro, 2017) to the intense exposures of Prolonged Exposure (PE; Foa, Hembree \& Rothbaum, 2007), all with the goal of reorganizing what has been dysfunctionally held in mind and body. Like other therapies, AEDP would hold that you 
have to "go there," to revisit the trauma, but would emphatically add that you do not have to go there alone: that the felt presence of a caring other, in and of itself changes the experience, and the way the experience is held in memory. Rosa states again and again that she is seeing this painful past with new eyes because her therapist is there with her, re-living the experience with her in a safe and titrated way, and self-disclosing her own reactions to the painful scenes. Traumatic memories are held vividly, close to the sights, sounds, and sensations of the experience. Vigoda Gonzales' empathic presence, combined with the shared Spanish language, allowed her to step more into those moments with Rosa, increasing AEDP's effectiveness.

\section{AN ENHANCED CAPACITY FOR JOY}

Another feature of AEDP that is powerfully evident in this case is that it aims not just at symptom relief, which was certainly achieved, and not just at character change, a goal of psychoanalytic depth work, but at a transformational experience and an enhanced capacity for joy. The trauma field has looked to Pierre Janet rather than Sigmund Freud as an early guide to how we carry the wounds of trauma and how we heal. A contemporary of Freud, Janet believed that reclaiming an experience as one's own, psychologically completing an incomplete action, should lead to an "act of triumph" and a state of joy. This is seen in AEDP as the focus on core affect, which emerges as a traumatic experience has been worked through to completion. We experience this completion in our whole body, not just as a cognition. To me, one of the delights of reading this case is to see those moments of joy, as therapist and client come through a difficult and painful journey into past trauma and through to the other side. It is not the grim satisfaction of seeing a bullet dug out; it is the much more joyful sense of having found a self that one had been separated from, a coming home to a fuller sense of one's own life.

This discovery of the capacity for joy highlights an important and unique contribution of AEDP with its focus on transformational affects. The case of Rosa is a vivid demonstration of this process. Accustomed to directing our focus in therapy to the painful feelings of guilt, shame, resentment, disappointment and fear with which clients struggle, we have not paid as much attention to positive feelings. AEDP turns our focus to these, and tracks them with great care, especially at the moments of reworking traumatically held memories and views of self (Fosha, 2004). Russell (2015, p. 97-98) discusses five transformational affects in her recent book, and they appear clearly in Vigoda Gonzales' work with Rosa in creating an enhanced capacity for joy.

- Healing affects happen when we feel emotionally moved and grateful and tender toward the other. Rosa had many moments where she felt moved at what was happening in the self and grateful to Vigoda Gonzales for facilitating and being present in those moments. In Rosa's words, "I am so glad that I am coming here" (p. 34).

- Mastery affects occur when we experience pride and joy. Rosa was a person of so many achievements, but because her family denigrated these and refused to see or honor them, she herself could never take them in and make them a part of her life narrative. One of the most moving parts of this case is to see the joy with which Rosa was able to recognize the courage and the achievement of her younger self: "Wow! I was doing pretty great for a little girl under those circumstances!" (p. 33) 
- Mourning the self occurs when we let ourselves take in the pain of what happened and what has been lost. We see this in Rosa in those moments when she inhabits the experiences of the younger self, so long shut away, and feels how painful it was. She revisits and reviews the many times she sought in vain her family's love and approval, and having experienced the pain of that deep disappointment, could say from a different place that "I'm ready to give that up," even though there was a part that was feeling like "I'm giving up the whole world" (p. 37). This allowed a new sense of compassion to emerge for the child she was.

- Tremulous affects show themselves in nervousness about something very new happening and a certain surprise and awe at what is happening. There is a lovely section in her case study where Vigoda Gonzales has Rosa repeat several times "there is nothing wrong with me" (e.g., p. 33). She says it only nervously at first, then with a breaking voice, and finally with exhilaration, which moves us into the territory of the next transformational affect, realization.

- Realization affects occur when we feel wonder, the "Yes" of something clicking into place and feeling right; it is the realization of the true. This happened multiple times in the narrative as Rosa makes remarks like, "I can't believe I have gotten to this place" (p. 39), reflecting a sense of wonder that emotional positions that felt impossible to shift were changed or left behind.

\section{STAGE 3: RECLAIMING A CONNECTION TO COMMUNITY}

The reclaiming of a connection to community, the reestablishment of trust and the enjoyment of social bonds, forms the third stage of trauma work. We see the beginnings of this with Rosa, as she attends a class she had been nervous about joining, as she engages more socially with others, and as her relationship with her son moves to a more adult to adult level, still with its pains and disappointments perhaps, but not as burdened with the distortions of the past or as many unmet needs. This was most beautifully put when Rosa says, "What this experience with you has given me is an appetite for going out and looking for other relations, because now there is something 'delicious' to look for in relationships." (p. 40). All three stages of trauma work are there, as we see Rosa's connection to her world has become different: starting from her establishment of safety, moving through her dark though accompanied journey into past pain, and emerging into a world no longer filled only with relationships that cause pain and despair, but a new world of wonders where relationships have the potential to be "delicious."

\section{THE SHORT-TERM NATURE OF THE WORK}

I also would like to say something about the short-term nature of the work. Our advanced students in our Clinical PsyD graduate program take this class in their last year of classwork, and are for the most part leaving on internship or to intensive external internships the following year. Therefore, the students are in the process of terminating their caseloads. Like all student clinics, this means the work has a built-in termination date. The class focuses on understanding several short-term models and on skill development in short-term therapy, an increasingly demanded modality in a resource-starved therapeutic world.

AEDP, while intensively going immediately to the heart of the client's pain and struggle in living, and therefore being quite time-effective, would not bill itself as a short-term treatment. I can imagine AEDP practitioners reading this narrative and feeling pained at the enforced termination of Rosa's work after only twenty-three sessions, thinking how much better it would 
have been, in such an attachment-focused therapy, to have it end on Rosa's terms, when she felt resourced enough, had gone through more cycles of the experience of core affect, and was more fully in the world as her emergent resilient self. I would agree with that.

However, this treatment still stands as an example of what can be accomplished even in a short amount of time. Those of us who work within time limits, whether imposed by agencies, insurance companies, or the circumstances of clients' lives, can take encouragement that significant and transformational work is possible, even when time is short. We should not therefore feel compelled to hold back, do supportive work only, or set only small goals. Vigoda Gonzales, with compassion, and carefully monitoring Rosa to see that the pace of the work was not too overwhelming, aimed higher. She sought to reconnect her with the buried trauma of childhood, to change that narrative, and to move toward a more compassionate view of the self. And though further gains could certainly be made from additional therapy, much was accomplished.

Vigoda Gonzales compares her paper to the earlier work of Pass (2012), which combined AEDP with a writing intervention. She notes that the two cases, both utilizing AEDP in trauma work, differed in that the Pass case would be considered a single-incident trauma occurring in the life of a person with a history of more secure attachments. Rosa's experience, which was the result of a conflicted and painful attachment history, is more likely to result in complex PTSD, when traumatic moments occur early and often. Complex PTSD is known for usually needing a longer-term treatment, and a more open-ended treatment clearly would have advantages. But the case demonstrates that substantial progress can be achieved with the fortunate combination of a client very responsive to an attachment-based approach and the integration of the therapist's sensitivity to the client's language of origin.

In discussing professional development with current students as well as graduates looking back on their education, they sometimes express disappointment in the relative absence of training in many of the specific models, methods and interventions which are currently exciting and enlivening practitioners in the field. This gap, perhaps similar in some ways to that between research and practice, between what currently excites practitioners and the training graduate students receive, may make our training less robust and effective than it might be. Because some of these models have arisen and flourished outside the academy, the academy does not always know how to integrate them. And the barrier exists on the other side as well, as practitioners who have developed these models and methods, wanting them to be appropriately applied, sometimes limit training to those already licensed in the field. This case demonstrates how integrating AEDP at the graduate student level can result both in good work that serves clients and potentially in the strengthening of training. In attending a variety of trainings in different current modalities, I am almost always surrounded by experienced, often senior, practitioners. This has been a pleasure and I am heartened by practitioners committed to lifelong learning and the integration of newer methods. When I work with students, I am often struck with how much more quickly they can integrate these methods than some of us who have been in the field for many years. Particularly when a student has found something that resonates, they are able to try it out and have an experience of success, unimpeded by having to overcome prior learning and practices that may pull in a different direction. Vigoda Gonzales' interventions serve as a good example of that. We could talk about metaprocessing, for example, meaning the many times 
Vigoda Gonzales asks Rosa, "What is it like for you to hear me say what I would do? To hear me say that it just makes me so angry?" (p.32). We could talk about self-disclosure to the client, both of her bilingualism and of feelings she had about Rosa. Vigoda Gonzales could try these out, certainly with the barriers to learning we all have when pushing ourselves into new territory, but without the internal crosstalk of previously learned models that would NOT endorse these interventions or the deeply grooved neural networks of years of practice in another style. Students are open to and able to learn these models, yet do not always have enough access to them. Training would be strengthened by improved integration.

\section{REFERENCES}

American Psychological Association. (2017). Multicultural guidelines: An ecological approach to context, identity, and intersectionality. Retrieved from: http://www.apa.org/about/policy/multicultural-guidelines.pdf

Bowlby, J. (1982). Attachment and loss: Vol. 1. Attachment (2d ed.) New York: Basic Books.

Foa, E., Hembree, E., \& Rothbaum, B.O. (2007). Prolonged exposure therapy for PTSD: Emotional processing of traumatic memories. New York: Oxford University Press.

Fosha, D. (2000). The transforming power of affect: A model for accelerated change. New York: Basic Books.

Fosha, D. (2004). 'Nothing that feels bad is ever the last step:' The role of positive emotions in experiential work with difficult emotional experiences. Clinical Psychology and Psychotherapy, 11, 30-43.

Fosha, D. (2006). Quantum transformation in trauma and treatment: Traversing the crisis of healing change. Journal of Clinical Psychology, 62, 569-583.

Gaztambide, D.J. (2012). Addressing cultural impasses with rupture resolution. Professional Psychology: Research and Practice, 43, 180-186.

Lipton, B., \& Fosha, D. (2011). Attachment as a transformative process in AEDP: Operationalizing the intersection of attachment theory and affective neuroscience. Journal of Psychotherapy Integration, 21(3), 253-279.

Pass, E.R. (2012). Combining expressive writing with an affect- and attachment-focused psychotherapeutic approach in the treatment of a single-incident trauma survivor: The case of "Grace." Pragmatic Case Studies in Psychotherapy, 8(2), Article 1, 60-112. Available: http://pcsp.libraries.rutgers.edu, http://dx.doi.org/10.14713/pcsp.v8i2

Porges, S.W. (2011). The polyvagal theory: Neurophysiological foundation of emotions, attachment, communication and self-regulation. New York: W.W. Norton.

Russell, E., \& Fosha, D. (2008). Transformational affects and core state in AEDP: The emergence and consolidation of joy, hope, gratitude, and confidence in (the solid goodness of) the self. Journal of Psychotherapy Integration, 18(2), 167-190.

Russell, E. (2015). Restoring resilience: Discovering your clients' capacity for healing. New York: W.W. Norton.

Shapiro, F. (2017). Eye movement desensitization and reprocessing (EMDR) therapy, third edition: Basic principles, protocols and procedures. New York: Guilford Press.

van der Kolk, B., \& Hart, O. (1990). Pierre Janet and the breakdown of adaptation in psychological trauma. American Journal of Psychiatry, 146(12), 1530-1540. 
Pragmatic Case Studies in Psychotherapy, http://pcsp.libraries.rutgers.edu

Volume 14, Module 1, Article 3, pp. 69-76, 09-12-18 [copyright by author]

Vigoda Gonzales, N. (2018). The merits of integrating accelerated experiential dynamic psychotherapy and cultural competence strategies in the treatment of relational trauma: The case of "Rosa. Pragmatic Case Studies in Psychotherapy, 14(1), Article 1, 1-57. Available: http://pcsp.libraries.rutgers.edu.

Walsh, S.D. (2014). The bilingual therapist and transference to language: Language use in therapy and its relationship to object relational context. Psychoanalytic Dialogues, 24(1) 56-71. 